\title{
Comparison of Cine-MRI and Transthoracic Echocardiography for the Assessment of Aortic Root Diameters in Patients with Suspected Marfan Syndrome
}

\section{Vergleich von Cine-MRT und transthorakaler Echokardiografie zur Erfassung des Aortenwurzeldiameters bei Patienten mit Verdacht auf Marfan-Syndrom}

Authors

Affiliations
P. Bannas ${ }^{1}$, M. Rybczynski ${ }^{2}$, S. Sheikhzadeh², Y. von Kodolitsch², T. Derlin ${ }^{1}$, J. Yamamura ${ }^{1}$, G. Lund ${ }^{1}$, G. Adam¹, M. Groth ${ }^{3}$

Affiliation addresses are listed at the end of the article.

\section{Key words}

- Marfan syndrome

- magnetic resonance imaging

- echocardiography

- aneurysm

- aorta received $\quad 25.12 .2014$

accepted $\quad 8.5 .2015$

Bibliography

DOI http://dx.doi.org/

10.1055/s-0035-1553224

Published online: 22.6.2015

Fortschr Röntgenstr 2015; 187:

1022-1028 @ Georg Thieme

Verlag KG Stuttgart · New York .

ISSN 1438-9029

\section{Correspondence \\ Dr. Michael Groth}

Department of Diagnostic and Interventional Radiology,

University Medical Center

Hamburg-Eppendorf

Martinistr. 52

20246 Hamburg

Germany

Tel.: ++ 49/40/428034029

Fax: ++49/40/428033802

groth.michael@googlemail.com

\section{Zusammenfassung}

$\nabla$

Ziel: Patienten mit einem Marfan-Syndrom benötigen eine regelmäßige Bildgebung zur Detektion von Aneurysmen der Aorta ascendens. Ziel dieser Studie war es, die Reproduzierbarkeit von Messungen des Sinus valsalvae mittels Cine-MRT und Echokardiografie an Patienten mit Verdacht auf Marfan-Syndrom zu untersuchen.

Material und Methoden: 51 konsekutive Patienten mit Verdacht auf Marfan-Syndrom wurden prospektiv mittels Cine-MRT und Echokardiografie untersucht. Jeweils zwei Auswerter bestimmten den Aortenwurzeldiameter auf Höhe des Sinus valsalvae mittels Cine-MRT und Echokardiografie. Die statistische Auswertung erfolgte mittels Intraklassen- sowie Pearson-Korrelationskoeffizient, Bland-Altman-Analyse sowie zweiseitigen t-Test.

Ergebnisse: Bei 38 der 51 Patienten (74,5\%) wurde ein Marfan-Syndrom entsprechend der Ghent-2Nosologie diagnostiziert. Es zeigte sich eine starke Korrelation zwischen den Diametermessungen des Sinus valsalvae mit der Cine-MRT und Echokardiografie $(r=0,929)$. Gleichzeitig konnte jedoch eine statistisch signifikante Messdifferenz von $-1 \mathrm{~mm}$ zwischen den beiden Modalitäten nachgewiesen werden $(\mathrm{p}<0,001)$. Der mittlere Diameter des Sinus valsalvae betrug $32,3 \pm 5,8 \mathrm{~mm}$ für die CineMRT verglichen mit 33,4 $\pm 5,4$ mm für die Echokardiografie. Die Interobserverübereinstimmung der Diametermessungen war signifikant besser für die Cine-MRT im Vergleich zur Echokardiografie $(\mathrm{p}=0,029)$.

Schlussfolgerung: Trotz kleiner, aber statistisch signifikanter Unterschiede der Übereinstimmung und Reproduzierbarkeit erreichen sowohl die CineMRT als auch die Echokardiografie vergleichbare Messwerte, welche mutmaßlich ohne klinisch relevante Differenz sind. Daher eignen sich beide Meth-

\section{Abstract \\ $\nabla$}

Purpose: Patients with Marfan syndrome require repeated imaging for monitoring of aortic root aneurysms. Therefore, we evaluated the agreement and reproducibility of cine-MRI and echocardiography measurements of the sinuses of Valsalva in patients with suspected Marfan syndrome.

Materials and Methods: 51 consecutive patients with suspected Marfan syndrome were prospectively examined using cine-MRI and echocardiography. Two readers independently measured aortic root diameters at the level of the sinuses of Valsalva in both cine-MRI and echocardiography. Statistics included intraclass correlation coefficient, Pearson correlation coefficient, Bland-Altman analysis, and two-sided t-test.

Results: In 38 of the 51 individuals (74.5\%), the diagnosis of Marfan syndrome was established according to the criteria of the Ghent-2 nosology. Cine-MRI measurements of the sinuses of Valsalva revealed a strong correlation with echocardiography $(r=0.929)$, but a statistically significant bias of $-1.0 \mathrm{~mm}(\mathrm{p}<0.001)$. The mean absolute diameter for sinuses of Valsalva obtained by cine-MRI was $32.3 \pm 5.8 \mathrm{~mm}$ as compared to $33.4 \pm 5.4 \mathrm{~mm}$ obtained by echocardiography. Interobserver agreement of measurements of the sinuses of Valsalva was higher for cine-MRI than for echocardiography ( $\mathrm{p}=0.029$ ).

Conclusion: Despite small, but statistically significant differences in terms of agreement and reproducibility, cine-MRI and echocardiographic measurements of aortic root diameters provide comparable results without a significant clinical difference. Therefore both techniques may be used for monitoring of the aortic root in patients with Marfan syndrome. 
oden zur Überwachung der Aortenwurzeldiameter von Patienten mit Marfan-Syndrom.

Kernaussagen:

- Cine-MRT (ICC: 0,93; CI: 0,88-0,96) und Echokardiografie (ICC: 0,90; CI: 0,82-0,94) sind zur Evaluation des Aortenbogens beim Marfan-Syndrom geeignet.

- Cine-MRT-Messungen der Aortenwurzel haben im Vergleich zur Echokardiografie eine höhere Reliabilität (mittlere Abweichung: +/- 3,6 mm versus +/- 5,0 mm; $p=0,029$ ).

- Mit Cine-MRT und Echokardiografie erhobene Aortenwurzelmessungen zeigen eine kleine (mittlere Messabweichung: - $1 \mathrm{~mm}$ ), aber statistisch signifikante Messdifferenz ( $\mathrm{p}=0,0004)$.
Key points:

- Cine-MRI (ICC: 0.93, CI: $0.88-0.96$ ) and echocardiography (ICC: 0.90, CI: $0.82-0.94$ ) allow assessment of aortic root diameters in patients with Marfan syndrome

- Cine-MRI offers higher reproducibility of aortic root diameters than echocardiography (95\% limits of agreement of $\pm 3.6 \mathrm{~mm}$ versus $\pm 5.0 \mathrm{~mm}, \mathrm{p}=0.029$ )

- Aortic root measurements with cine-MRI and echocardiography reveal a small (mean difference; $-1.0 \mathrm{~mm}$ ) but statistically significant offset $(\mathrm{p}=0.0004)$

Citation Format:

- Bannas P., Rybczynski M., Sheikhzadeh S. et al. Comparison of Cine-MRI and Transthoracic Echocardiography for the Assessment of Aortic Root Diameters in Patients with Suspected Marfan Syndrome. Fortschr Röntgenstr 2015; 187: 1022-1028

\section{Introduction}

With a prevalence ranging between 1 and 2 in 10000 [1], Marfan syndrome is the most common syndromic presentation of ascending aortic aneurysm with a high risk of aortic dissection, rupture and pericardial tamponade $[1,2]$. Current therapy for the cardiovascular complications of Marfan syndrome includes medical management in order to slow down the rate of aortic root dilatation and surgery to prevent dissection when the aortic root reaches a diameter of $4.5 \mathrm{~cm}$ or is growing at a rate of more than $0.5 \mathrm{~cm}$ per year [ $1-5]$.

Since lifelong yearly imaging of the aortic root in patients with Marfan syndrome is mandatory, a reliable, reproducible and operator-independent imaging technique for assessing the exact diameter of the aortic root, specifically at the level of the sinuses of Valsalva is needed to improve the selection of candidates for elective operation $[3,5]$. The noninvasive imaging methods, echocardiography, computed tomography (CT), and cardiac magnetic resonance imaging (MRI) are alternative diagnostic options [3]. Echocardiography is an established modality for assessing aortic root diameters. However, a recent study reported echocardiography-derived aortic root diameters to display higher variability compared with cine-MRI and CT in a study collective of patients with severe aortic stenosis, who underwent evaluation for transcatheter aortic valve implantation (TAVI) [6]. Because of contrastmedia-independent MRI sequences and no radiation exposure, MRI may be preferred over CT [3].

To our knowledge, cine-MRI has not yet been used for aortic root measurements in a larger series of selected patients with suspected Marfan syndrome to assess the precision of this imaging technique. We focused on the exact assessment of the diameter at the level of the sinuses of Valsalva, because this diameter is critical for the indication of surgical aortic root replacement $[1,2,5]$. Hence, the purpose of our prospective study was to determine the agreement and reproducibility of cine-MRI and echocardiography in aortic root assessment in patients with known or suspected Marfan syndrome.

\section{Materials and Methods}

$\nabla$

\section{Study collective}

The prospective study was approved by the local ethics committee, and all patients provided written informed consent. The study collective consisted of 51 consecutive patients with sus- pected Marfan syndrome, who had also been included in another previously published investigation [7]. Results of one of the echocardiographic readers have been reported in the previous study. However, the results of the other echocardiographic reader and the cine-MRI results have not been reported. The aims of the studies are unrelated and do not meet redundant publication criteria. All patients underwent the routine transthoracic echocardiographic (TTE) examination, which is included in the standard clinical protocol for patients with known or suspected Marfan syndrome in our University Marfan Center. All patients were in stable clinical condition and underwent an MR examination of the thoracic aorta the same day as the echocardiographic examination.

Indications for study inclusion compromised suspected or known Marfan syndrome. Subjects with suspected Marfan syndrome were either relatives of patients with confirmed Marfan syndrome or subjects with clinical suspicion of Marfan syndrome or another genetic aortic disease. Marfan syndrome was established with the criteria of the current Ghent-2 nosology with sequencing of the FBN1 gene in all individuals $[8,9]$. The 2010 revised Ghent-2 nosology for Marfan syndrome relies on seven rules as indicated in Table 1. The new diagnostic criteria put more weight on the cardiovascular manifestations of the disorder. Aortic root aneurysm is now a cardinal feature. Patients were excluded from the study if they had contraindications to MR imaging such as an implanted pacemaker or severe claustrophobia.

Table 1 Diagnostic criteria of Marfan syndrome (MFS) according to the Ghent-2 nosology.

Tab. 1 Diagnosekriterien des Marfan-Syndroms (MFS) basierend auf der Ghent-2-Nosologie.

in the absence of family history:

(1) aortic root diameter (Z-score $\geq 2$ ) AND ectopia lentis = MFS

(2) aortic root diameter ( $Z$-score $\geq 2$ ) AND causal FBN1 mutation = MFS

(3) aortic root diameter (Z-score $\geq 2$ ) AND systemic score $\geq 7$ points $=$ MFS $^{1}$

(4) ectopia lentis and causal FBN1 mutation with known aortic root dilatation $=$ MFS

in the presence of family history:

(5) ectopia lentis AND family history of MFS = MFS

(6) systemic score $\geq 7$ points AND family history of MFS $=$ MFS $^{1}$

(7) aortic root diameter ( $Z$-score $\geq 2$ above 20 years old, $\geq 3$ below 20 years) and family history of MFS $=$ MFS

${ }^{1}$ Features suggestive of Sphrintzen-Goldberg syndrome, Loeys-Dietz syndrome or vascular form of Ehlers-Danlos syndrome must be excluded. 


\section{Cardiac MR imaging}

MR imaging was performed using a 1.5 Tesla scanner (Magnetom Symphony, Siemens, Erlangen, Germany) software VA30 with a four-element phased-array chest coil and electrocardiographic triggering. For cardiac triggering ECG leads were placed in a standardized manner before positioning the patient inside the magnetic bore. At the beginning of every examination, scout images were performed in axial, coronal and sagittal orientation. Cine-MR imaging was performed with a prospectively triggered steady-state free precision sequence (TrueFISP; Siemens). Imaging parameters were: repetition time msec/echo time msec, $3.6 / 1.8$; section thickness, $8 \mathrm{~mm}$; field of view, $350 \times 306 \mathrm{~mm}$ (8:7 rectangular field of view); matrix, $256 \times 224$; pixel size, $1.37 \times 1.37 \mathrm{~mm}$. Sequences lasted approximately $12-15$ seconds depending on the heart rate. Cine-MR images were acquired during breath hold to acquire the standard cardiac views. The left ventricular outflow tract (LVOT) cine was planned by using the end-diastolic frame from the basal slice of the short-axis cine. An orthogonal imaging plane was rotated so that it passed through the aortic valve and up into the ascending thoracic aorta, which was confirmed on the axial scout images. This produced an LVOT cine, which is equivalent to the parasternal long-axis view on echocardiography [10].

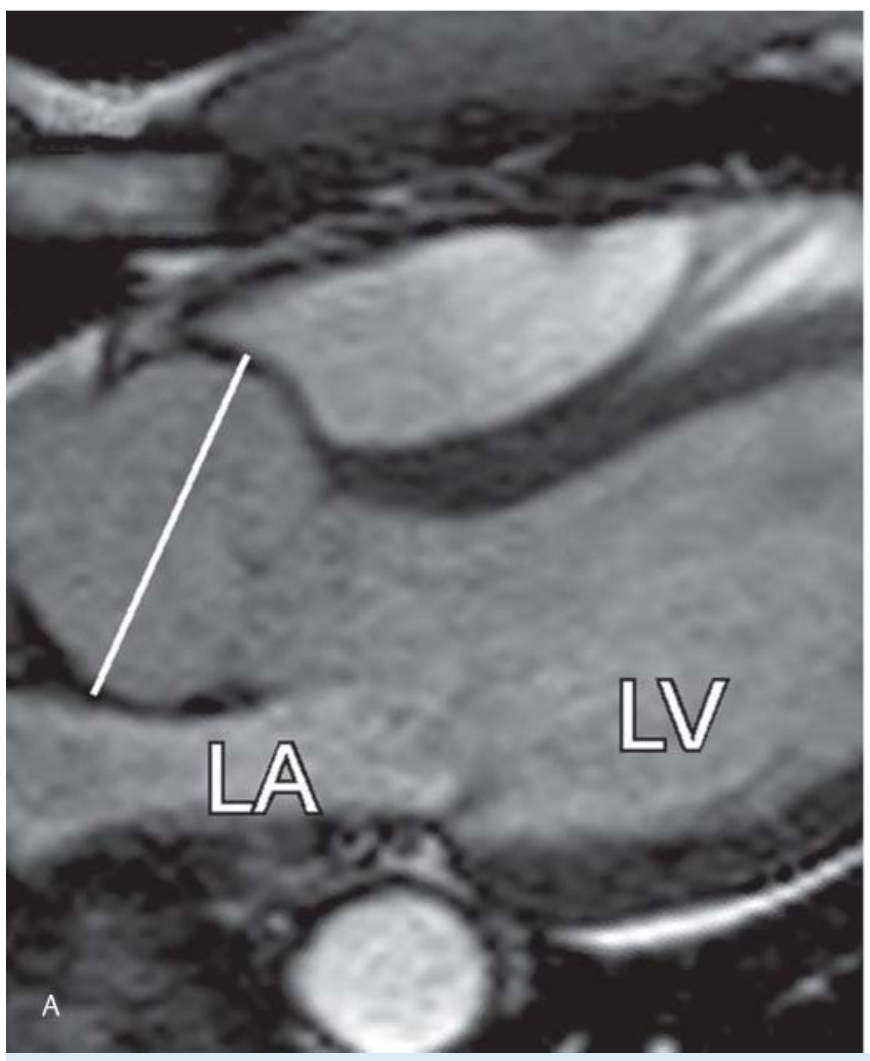

Fig. 1 Cine-MRI and echocardiography of a 41-year-old male patient with confirmed Marfan syndrome. A Left ventricular outflow tract cine on cardiac MRI and $\mathbf{B}$ parasternal long axis view on echocardiography with indicated level of aortic root diameter assessment at the level of the sinuses of Valsalva. A Note the clear delineation of the aortic root on cine-MRI. B 2 D transthoracic echocardiography also offers sufficient imaging quality of the aortic root. LA, left atrium; LV, left ventricle. The diameter of the sinuses of Valsalva was determined by the readers as $44 \mathrm{~mm}$ and $45 \mathrm{~mm}$, respectively, with cine-MRI and as $45 \mathrm{~mm}$ by both readers with echocardiography.

\section{Cardiac MR image evaluation}

Two radiologists, P. B. (5 years of experience) and M. G. (6 years of experience), independently evaluated the cine-MR images in random order. Images were not blinded, since readers were assessing only one type of image and were aware of the study collective of patients with suspected Marfan syndrome. The inner end-diastolic diameter of the aorta was measured perpendicular to the blood flow [3] at the level of the sinuses of Valsalva using the LVOT cine as displayed in $\mathbf{O}$ Fig. 1A. For assessment of interobserver agreement, independent measurements were performed by P. B. and by M. G. A standard window level was applied for all measurements and image quality evaluation.

\section{Echocardiographic examination and image evaluation}

2D-transthoracic echocardiographic examinations were performed by experienced cardiologists, either by M.R. (11years of experience) or by S.S. (7 years of experience) with a commercially available ultrasound system (iE33, Philips Healthcare, Best, The Netherlands). End-diastolic aortic root diameters were determined at the level of the sinuses of Valsalva using the parasternal long-axis view as displayed in O Fig. 1B [11]. For assessment of interobserver agreement, independent measurements were performed by M.R. and by S.S.

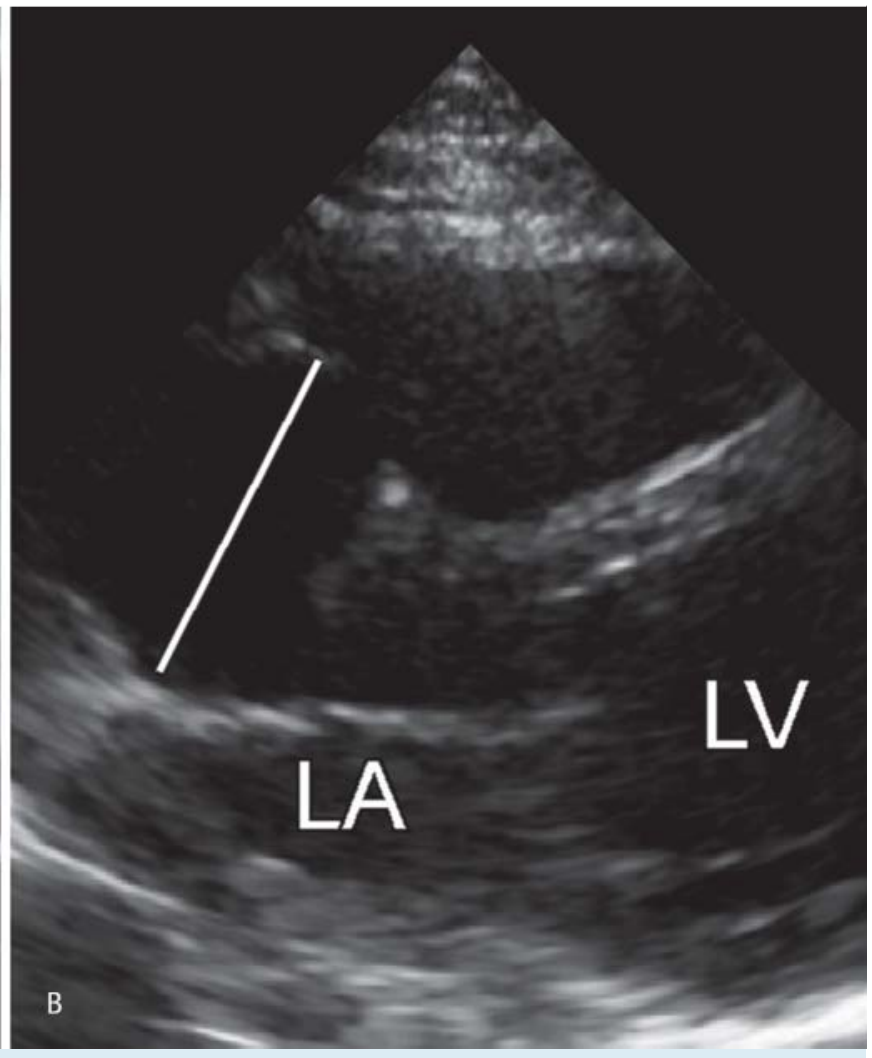

Abb.1 Cine-MRT und Echokardiografie eines 41-jährigen Patienten mit bestätigtem Marfan-Syndrom. A Linksventrikulärer Ausflusstrakt in der Cine-MRT und $\mathbf{B}$ parasternal lange Achse in der Echokardiografie. Die Linien deuten die Messebene der Aortenwurzel auf Höhe des Sinus valsalvae an. A Mittels Cine-MRT kann die Aortenwurzel scharf abgegrenzt werden. B Auch mittels der Echokardiografie kann die Aortenwurzel suffizient abgebildet werden. LA, linkes Atrium; LV, linker Ventrikel. Der Diameter des Sinus valsalvae wurde in der Cine-MRT von den beiden Auswertern mit $44 \mathrm{~mm}$ bzw. $45 \mathrm{~mm}$ bestimmt, und in der Echokardiografie von beiden Auswertern mit $45 \mathrm{~mm}$. 


\section{Statistical analysis}

Intraclass correlation coefficient (ICC) with $95 \%$ confidence intervals $(\mathrm{CI})$ and Bland-Altman analysis were used to investigate the interobserver agreement of measurements obtained from cardiac MRI and echocardiography. Differences of the ICC were considered statistically significant if the mean $\pm 95 \%$ confidence intervals did not overlap. An F-test was performed for comparison of variances [12].

Pearson's correlation was calculated to determine the correlation between diameters assessed by cardiac MRI and echocardiography. Correlation coefficients greater than 0.8 indicated a strong correlation. Coefficients ranging from 0.5 to 0.8 indicated a moderate correlation whereas coefficients ranging from 0.3 to 0.49 indicated a weak correlation and coefficients smaller than 0.3 were interpreted as an almost non-existent correlation [13]. Bland-Altman analysis was used to assess agreement and bias between measurements obtained from cardiac MRI and echocardiography. A two-sided paired t-test was used to determine if there was a significant difference between the measurements obtained from cardiac MRI and echocardiography. $P<0.05$ indicated statistical significance. Statistical analysis was performed using commercially available software (MedCalc for Windows, Mariakerke, Belgium and Excel, Microsoft Corporation, Redmond WA USA). Data are presented as means \pm standard deviations.

\section{Results}

$\nabla$

\section{Patients}

Cine-MRI and echocardiography were performed successfully in all 51 patients ( 25 female, 26 male; mean age, $37.1 \pm 13.7$ years) without technical problems. In 38 of the 51 individuals (74.5\%), the diagnosis of Marfan syndrome was established according to the criteria of the Ghent-2 nosology. The remaining 13 patients (25.5\%) did not fulfil the diagnostic criteria of Marfan syndrome or any other defined genetic aortic tissue disease. Measurements of the aortic root at the level of the sinuses of Valsalva were performed in all 51 patients by two observers using cine-MRI and echocardiography ( $\bullet$ Fig. 1 ).

Interobserver agreement of cine-MRI and transthoracic echocardiography

The ICC of the interobserver agreement for measurements of the sinuses of Valsalva was higher for cine-MRI (0.93, CI: $0.88-0.96)$ than for echocardiography $(0.90, \mathrm{CI}: 0.82-0.94)$. This difference was not statistically significant, since confidence intervals overlap. At Bland-Altman analysis, cine-MRI revealed a mean interobserver bias of $-1.2 \mathrm{~mm}$ and echocardiography a mean bias of $0.8 \mathrm{~mm}$. Comparing the variances of measurements, cine-MRI of the sinuses of Valsalva revealed a significantly smaller $(p=0.029)$ interobserver variance ( $95 \%$ limits of agreement, $\pm 3.6 \mathrm{~mm}$ ) than echocardiography ( $95 \%$ limits of agreement, $\pm 5.0 \mathrm{~mm}$ ) (৫ Fig. 2 , - Table 2).

\section{Comparison of cine-MRI and echocardiographic measurements}

Pearson's correlation revealed a strong correlation $(r=0.929)$ for cine-MRI measurements of the sinuses of Valsalva with echocardiographic measurements. At Bland-Altman analysis, cine-MRI of the sinuses of Valsalva revealed a significant bias $(p=0.0004)$ (mean difference; $-1.0 \mathrm{~mm}$ ) as compared with measurements obtained by echocardiography ( $\bullet$ Fig. 3, $\odot$ Table 3 ). The mean abso-

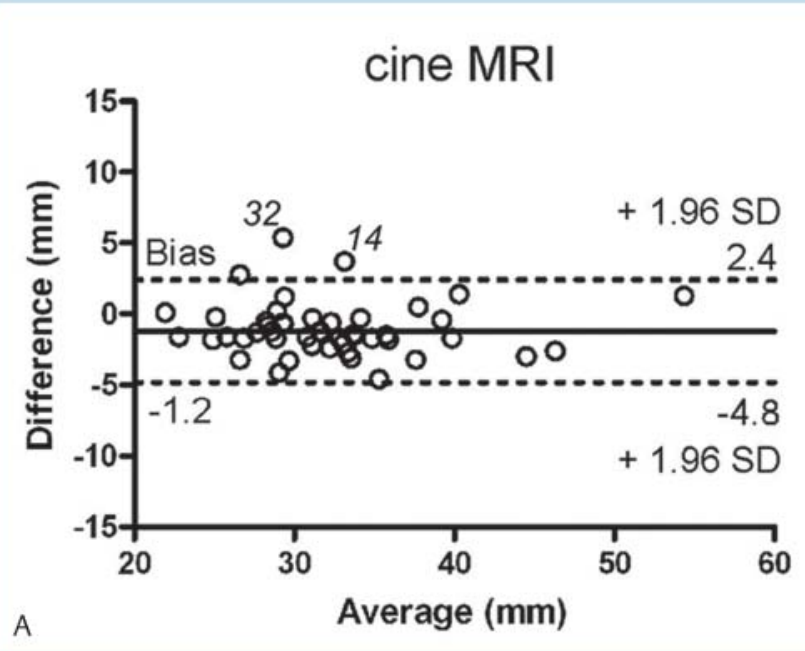

Fig. 2 Interobserver agreement of aortic root measurements. Bland-Altman plots of interobserver agreement with $\mathbf{A}$ cine-MRI $(-1.2 \pm 1.8 \mathrm{~mm})$ and B echocardiography $(0.8 \pm 2.5 \mathrm{~mm})$, confirming a significantly higher interobserver variance of echocardiography $(p=0.029)$. Middle solid line indicates mean bias, and dotted lines indicate limits of agreement. The reason for the 2 outliers with cine-MRI is that one reader underestimated and the other overestimated the diameter by $2 \mathrm{~mm}$ and $3 \mathrm{~mm}$, respectively, giving rise to a total bias of $4 \mathrm{~mm}(\# 14)$ and $5 \mathrm{~mm}(\# 32)$. The outlier with echocardiography (\#14) can be explained by the fact that this patient had a pectus excavatum and echocardiography had to be performed in the right parasternal view, resulting in suboptimal image quality.

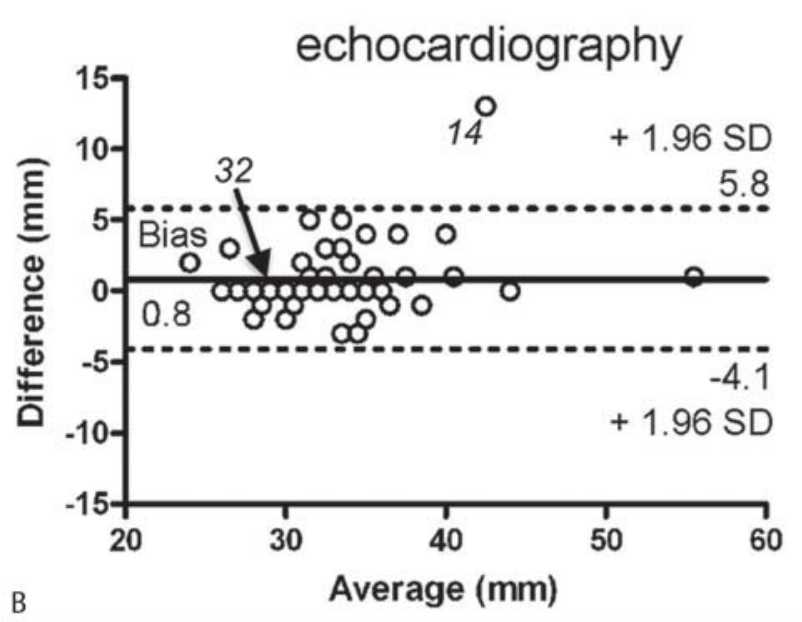

Abb. 2 Interobserverdifferenz von Messungen der Aortenwurzel. BlandAltman Diagramme der Interobserverdifferenzen von A Cine-MRT (- 1,2 $\pm 1,8 \mathrm{~mm})$ und B Echokardiografie $(0,8 \pm 2,5 \mathrm{~mm})$ zeigen eine signifikant höhere Interobservervarianz der Echokardiografie $(p=0,029)$. Die durchgehende mittlere Linie entspricht der mittleren Differenz und die gestrichelte Linie den Agreement Limits. Die zwei Ausreißer in der Cine-MRT sind dadurch zu erklären, dass die beiden Auswerter die Diameter jeweils um 2 bzw. 3 mm über- bzw. unterschätzt haben, wodurch sich ein Bias von $4 \mathrm{~mm}$ (\#14) bzw. $5 \mathrm{~mm}$ (\#32) ergab. Bei dem Ausreißer in der Echokardiografie handelte es sich um einen Patienten mit Trichterbrust. Daher musste von rechts parasternal geschallt werden, was in einer suboptimalen Abbildungsqualität resultierte. 
Table 2 Interobserver variance of measured aortic diameters as determined by cardiac cine-MRI and echocardiography as described by Bland and Altman. ICC values are given for both techniques. F-test was performed for comparison of variances. Numbers in parentheses indicate $95 \%$ confidence intervals.

Tab. 2 Interobserver Varianz der mittels Cine-MRT und Echokardiografie gemessenen Aortendiameter nach Bland und Altman. ICC-Werte wurden für beide Modalitäten angegeben. Ein F-Test wurde zum Vergleich der Varianzen durchgeführt. Die $95 \%$-Konfidenzintervalle sind in Klammern angegeben.

\begin{tabular}{|ll|}
\hline & cine MRI \\
\hline - mean difference $(\mathrm{mm})$ & -1.2 \\
\hline - limits of agreement $(\mathrm{mm})$ & -4.8 and 2.4 \\
\hline - standard deviation $(\mathrm{mm})$ & 1.8 \\
\hline - variance $\left(\mathrm{mm}^{2}\right)$ & 3.24 \\
\hline - intraclass correlation coefficient $(\mathrm{r})$ & $0.93(0.88-0.96)$ \\
\hline & echocardiography \\
\hline - mean difference $(\mathrm{mm})$ & 0.8 \\
\hline - limits of agreement $(\mathrm{mm})$ & -4.1 and 5.8 \\
\hline - standard deviation $(\mathrm{mm})$ & 2.5 \\
\hline - variance $(\mathrm{mm} 2)$ & 6.25 \\
\hline - intraclass correlation coefficient $(\mathrm{r})$ & $0.90(0.82-0.94)$ \\
\hline p-value (F-Test) & 0.029 \\
\hline
\end{tabular}

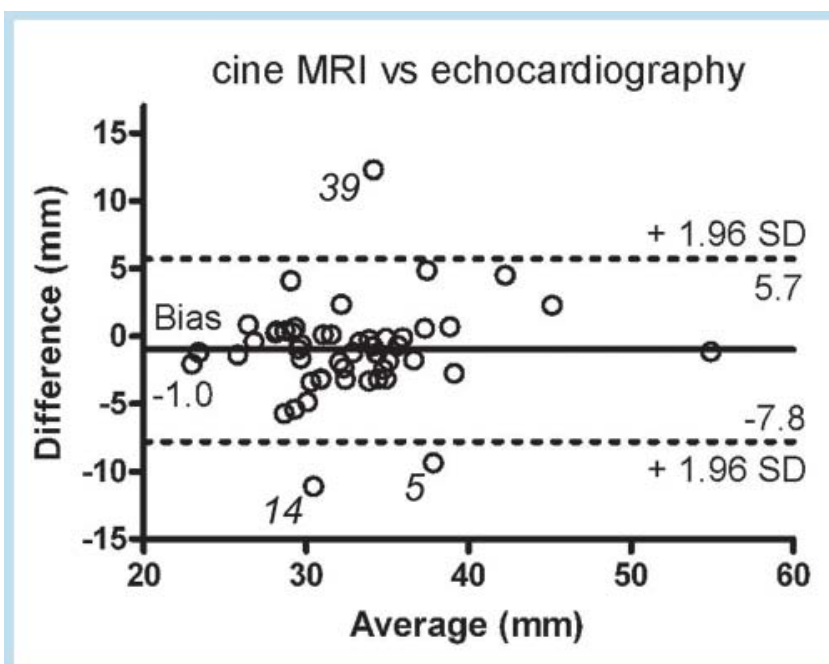

Fig. 3 Bland-Altman comparison for diameters of sinuses of Valsalva assessed by cine-MRI and echocardiography. Bland-Altman graph data indicate good agreement between cardiac MRI and echocardiography, however with a significant mean difference $(p=0.0004)$ of $-1.0 \pm 3.4 \mathrm{~mm}$. Cine-MRI revealed a strong correlation with echocardiography ( $r=0.929)$. Middle solid line indicates mean bias, and dotted lines indicate limits of agreement. Two (\#14, \#39) of the three outliers had a pectus excavatum and echocardiography had to be performed in the right parasternal view, resulting in suboptimal image quality. In the third case (\#5) the discrepancy might be explained by a different orientation between MRI and echo measurements.

Abb. 3 Bland-Altman Vergleich der Diametermessungen des Sinus valsalvae mittels Cine-MRT und Echokardiografie. Das Bland-Altman-Diagramm zeigt eine gute Übereinstimmung zwischen der Cine-MRT und der Echokardiografie bei jedoch einer signifikanten Messdifferenz $(p=0,0004)$ von $-1,0 \pm 3,4 \mathrm{~mm}$. Darüber hinaus kann eine starke Korrelation zwischen CineMRT und Echokardiografie nachgewiesen werden $(r=0,929)$. Die durchgehende mittlere Linie entspricht der mittleren Differenz und die gestrichelte Linie den Agreement Limits. Bei zwei der Ausreißer (\#14, \#39) handelte es sich um Patienten mit Trichterbrust. Daher musste von rechts parasternal geschallt werden, was in einer suboptimalen Abbildungsqualität resultierte. Bei dem dritten Ausreißer (\#5) ist die Diskrepanz vermutlich auf eine unterschiedliche Orientierung der Cine-MRT und der Echokardiografie Messungen zurückzuführen.
Table 3 Comparison of aortic diameters at the level of the sinus of Valsalva as determined by cine-MRI and echocardiography as described by Bland and Altman. T-test was performed for comparison of mean diameters.

Tab. 3 Vergleich der Aortendiameter auf Höhe des Sinus Valsalvae mittels Cine-MRT und Echokardiografie nach Bland und Altman. Mittels eines t-Tests wurden die mittleren Diameter verglichen.

\begin{tabular}{|ll|}
\hline - cine-MRI $(\mathrm{mm})$ & $32.3 \pm 5.8$ \\
\hline - echocardiography $(\mathrm{mm})$ & $33.4 \pm 5.4$ \\
\hline - mean difference $(\mathrm{mm})$ & -1.0 \\
\hline - limits of agreement $(\mathrm{mm})$ & -7.8 and 5.7 \\
\hline - standard deviation $(\mathrm{mm})$ & 3.4 \\
\hline - variance $(\mathrm{mm} 2)$ & 11.56 \\
\hline p-value (t-Test) & 0.0004 \\
\hline
\end{tabular}

lute diameter for sinuses of Valsalva obtained by cine-MRI was $32.3 \pm 5.8 \mathrm{~mm}$ as compared to $33.4 \pm 5.4 \mathrm{~mm}$ obtained by echocardiography.

\section{Discussion \\ $\nabla$}

Our study confirmed that both cine-MRI and echocardiography allow assessment of aortic root diameters in patients with Marfan syndrome. Our results demonstrated a higher reproducibility of cine-MRI measurements of the sinuses of Valsalva in patients with suspected Marfan syndrome when compared to transthoracic echocardiography. Moreover, we found a small but significant offset between cine-MRI and echocardiographic measurements.

Recent studies have compared cine-MRI and echocardiography for imaging of the aortic root in various study collectives other than patients with Marfan syndrome and stated that cine-MRI offers more precise measurements of the aortic root $[6,14]$. However, results from these studies might not be transferable to special patient populations such as patients suffering from Marfan syndrome. Marfan patients may often present with considerable deformities of the thoracic skeleton including different degrees of pectus excavatum [15], rendering echocardiography more difficult than in the general population [16]. Indeed, our study revealed that MRI offered more precise measurements of the aortic root in our collective of patients with suspected or known Marfan Syndrome.

Because of the large clinical variability and genetic heterogeneity, Marfan syndrome remains a clinical diagnosis based on different features classified into major and minor criteria. Aortic root dilatation is one of the major criteria for establishing the diagnosis of Marfan syndrome [9]. Selecting the most appropriate imaging method may depend on patient-related factors and institutional skills. Contrast-enhanced MRA of the aorta allows to assess aortic root diameters [17 - 20]. However, gadolinium agents for MR imply the risk of nephrogenic fibrosis (NSF) [21-24]. Hence non-enhanced MRI techniques like cine-MRI are desirable for repetitive imaging without the risk of adverse effects. Moreover, most of the available contrast-enhanced MRA techniques are not ECG-triggered and therefore lead to a higher intra- and interobserver variability as compared to non-contrast ECG-triggered MR techniques $[7,20]$. A further advantage of non-enhanced MRI compared to contrast-enhanced MRA is that determination of the contrast material arrival time at the thoracic aorta is dispensable. Thus the non-enhanced trueFISP sequence offers optimal contrast to noise regardless of timing for image acquisition $[18,25]$. Another advantage of the ECG-gated 2D cine sequence is its rapid acquisition 
time of $12-15$ seconds, which is advantageous especially in children or patients with claustrophobia. In addition, due to its short acquisition time, cine-MRI of the aortic root can easily be repeated, if motion artifacts or selection of the wrong imaging plane might hamper exact image evaluation.

Our results revealed that when comparing the diameter of the sinuses of Valsalva of cine-MRI measurements in LVOT view with results of transthoracic echocardiography in the parasternal longaxis view, a small but significant offset of $-1.0 \mathrm{~mm}$ has to be taken into consideration, likely due to the different imaging modalities and slight differences in the orientation of the measurements. Our observed offset is higher than reported in a recent study on aortic measurements in patients eligible for TAVI, where an offset of $0.5 \mathrm{~mm}$ has been noted [6]. Interestingly, a recent study by Hoey et al. has found that cine-MRI produces higher measurements $(+2.0 \mathrm{~mm})$ than echocardiography [26]. This discrepant finding is likely explained by the fact that Hoey et al. measured the cuspcommissure dimension on cross-sectional through-plane images, while we measured the diameters on LVOT images.

In chronic aortic conditions, like Marfan syndrome, serial comparison to previous imaging studies is required, and future imaging studies are expected during follow-up [3, 27]. Longitudinal changes over time and critical expansion are key issues and need to be addressed in the chronic setting. Hence, we suggest performing ECG-gated MRI, but under consideration of the offset when comparing results with previous echocardiographic results. Moreover, we recommend sticking to one selected imaging method, preferably ECG-gated MRI, like cine-MRI, for exact monitoring of the longitudinal progression of aortic root dilatation and appropriate timing for surgery.

Some limitations of our study have to be mentioned: First, we did not compare other MRI sequences like $3 \mathrm{D}$ sequences with our $2 \mathrm{D}$ cine-MRI sequence. Previous studies have compared $2 \mathrm{D}$ cineMRI sequences with $3 \mathrm{D}$ non-contrast MRI and revealed that the $2 \mathrm{D}$ sequences had the highest interobserver correlation. However, after critical evaluation of their data, the authors stated that this might be due to the fact that the imaging plane for cine-MRI is prescribed at the time of the scan by the technologist and later measurements are performed at this same source plane by all readers leading to a good correlation [28]. Nevertheless, this limitation is the same for echocardiographic measurements, since echocardiographic imaging was performed once by one observer per patient in our study. Hence, the chosen imaging plane might have influenced aortic MRI as well as echocardiographic measurements. However, a comprehensive study design would need to include two cardiologists who both perform independent echo examinations and two repeated complete MRI examinations (i.e., starting each with a new localizer). To further reflect clinical reality, the patients should get up and lie down again between the two echo and MRI examinations. Second, we did not assess other MR imaging planes of the aortic root. However, this was not the aim of our study and has been performed previously by others groups, who have shown that different diameters of the aorta are obtained depending on the orientation of measurements [29].

\section{Conclusion}

$\nabla$

Despite small but statistically significant differences in terms of agreement and reproducibility, cine-MRI and echocardiographic measurements of aortic root diameters provide comparable re- sults without a significant clinical difference. Both techniques may be used for the monitoring of the aortic root in patients with Marfan syndrome.

\section{Affiliations}

Department of Diagnostic and Interventional Radiology, University Medical Center Hamburg-Eppendorf, Hamburg, Germany

2 Department of General and Interventional Cardiology, University Medical Center Hamburg-Eppendorf, Hamburg, Germany

3 Department of Diagnostic and Interventional Radiology, Section for Pediatric Radiology, University Medical Center Hamburg-Eppendorf, Hamburg, Germany

\section{References}

1 Pearson GD, Devereux R, Loeys B et al. Report of the National Heart, Lung, and Blood Institute and National Marfan Foundation Working Group on research in Marfan syndrome and related disorders. Circulation 2008; 118: $785-791$

2 Judge DP, Dietz HC. Marfan's syndrome. Lancet 2005; 366: 1965 - 1976

3 Hiratzka LF, Bakris GL, Beckman JA et al. 2010 ACCF/AHA/AATS/ACR/ ASA/SCA/SCAI/SIR/STS/SVM Guidelines for the diagnosis and management of patients with thoracic aortic disease. A Report of the American College of Cardiology Foundation/American Heart Association Task Force on Practice Guidelines, American Association for Thoracic Surgery, American College of Radiology, American Stroke Association, Society of Cardiovascular Anesthesiologists, Society for Cardiovascular Angiography and Interventions, Society of Interventional Radiology, Society of Thoracic Surgeons, and Society for Vascular Medicine. J Am Coll Cardiol 2010; 55: e27-e129

4 Svensson LG, Kouchoukos NT, Miller DC et al. Expert consensus document on the treatment of descending thoracic aortic disease using endovascular stent-grafts. Ann Thorac Surg 2008; 85: S1 -S41

5 Gott VL, Greene PS, Alejo DE et al. Replacement of the aortic root in patients with Marfan's syndrome. N Engl J Med 1999; 340: 1307 - 1313

6 Jabbour A, Ismail TF, Moat $N$ et al. Multimodality imaging in transcatheter aortic valve implantation and post-procedural aortic regurgitation: comparison among cardiovascular magnetic resonance, cardiac computed tomography, and echocardiography. J Am Coll Cardiol 2011; 58: 2165 - 2173

7 Bannas P, Groth M, Rybczynski M et al. Assessment of aortic root dimensions in patients with suspected Marfan syndrome: intraindividual comparison of contrast-enhanced and non-contrast magnetic resonance angiography with echocardiography. International journal of cardiology 2013; 167: 190-196

8 Sheikhzadeh S, Kade C, Keyser B et al. Analysis of Phenotype and Genotype Information for the Diagnosis of Marfan Syndrome. Clin Genet 2012; 82: $240-247$

9 Loeys BL, Dietz HC, Braverman AC et al. The revised Ghent nosology for the Marfan syndrome. J Med Genet 2010; 47: 476-485

10 Plein S. Cardiovascular MR Manual. Springer; 2011

11 Roman MJ, Devereux RB, Kramer-Fox R et al. Two-dimensional echocardiographic aortic root dimensions in normal children and adults. Am J Cardiol 1989; 64: 507-512

12 Groth M, Muellerleile K, Klink T et al. Improved agreement between experienced and inexperienced observers using a standardized evaluation protocol for cardiac volumetry and infarct size measurement. Rofo 2012; 184: 1131 - 1137

13 Groth M, Henes FO, Bannas P et al. Intraindividual comparison of contrast-enhanced MRI and unenhanced SSFP sequences of stenotic and non-stenotic pulmonary artery diameters. RoFo: Fortschritte auf dem Gebiete der Rontgenstrahlen und der Nuklearmedizin 2011; 183 : 47 53

14 La Manna A, Sanfilippo A, Capodanno D et al. Cardiovascular magnetic resonance for the assessment of patients undergoing transcatheter aortic valve implantation: a pilot study. J Cardiovasc Magn Reson 2011; 13: 82

$15 \mathrm{Ha} \mathrm{HI}$, Seo JB, Lee SH et al. Imaging of Marfan syndrome: multisystemic manifestations. Radiographics 2007; 27: 989-1004

16 Oezcan S, Attenhofer Jost CH, Pfyffer M et al. Pectus excavatum: echocardiography and cardiac MRI reveal frequent pericardial effusion and 
right-sided heart anomalies. Eur Heart J Cardiovasc Imaging 2012; 13 : $673-679$

17 Kawamoto S, Bluemke DA, Traill TA et al. Thoracoabdominal aorta in Marfan syndrome: MR imaging findings of progression of vasculopathy after surgical repair. Radiology 1997; 203: 727-732

18 Kreitner KF, Kunz RP, Kalden P et al. Contrast-enhanced three-dimensional MR angiography of the thoracic aorta: experiences after 118 examinations with a standard dose contrast administration and different injection protocols. Eur Radiol 2001; 11: 1355-1363

19 Bannas $P$, Groth M, Rybczynski $M$ et al. Assessment of aortic root dimensions in patients with suspected Marfan syndrome: Intraindividual comparison of contrast-enhanced and non-contrast magnetic resonance angiography with echocardiography. Int J Cardiol 2012; DOI: S0167-5273(11)02222-4 [pii] 10.1016/j.ijcard.2011.12.041

20 Veldhoen S, Behzadi C, Derlin T et al. Exact monitoring of aortic diameters in Marfan patients without gadolinium contrast: intraindividual comparison of 2D SSFP imaging with 3D CE-MRA and echocardiography. Eur Radiol 2014; DOI: 10.1007/s00330-014-3457-6

21 Francois $C J$, Tuite $D$, Deshpande $V$ et al. Unenhanced MR angiography of the thoracic aorta: initial clinical evaluation. Am J Roentgenol 2008; 190: $902-906$

22 Wertman R, Altun E, Martin DR et al. Risk of nephrogenic systemic fibrosis: evaluation of gadolinium chelate contrast agents at four American universities. Radiology 2008; 248: 799-806

23 Broome DR. Nephrogenic systemic fibrosis associated with gadolinium based contrast agents: a summary of the medical literature reporting. Eur J Radiol 2008; 66: 230-234
24 Shellock FG, Spinazzi A. MRI safety update 2008: part 1, MRI contrast agents and nephrogenic systemic fibrosis. Am J Roentgenol 2008; 191: $1129-1139$

25 Krishnam MS, Tomasian A, Deshpande $V$ et al. Noncontrast 3D steadystate free-precession magnetic resonance angiography of the whole chest using nonselective radiofrequency excitation over a large field of view: comparison with single-phase 3D contrast-enhanced magnetic resonance angiography. Invest Radiol 2008; 43: 411-420

26 Hoey ET, Pakala V, Kassamali RH et al. A comparative analysis of ECGgated steady state free precession magnetic resonance imaging versus transthoracic echocardiography for evaluation of aortic root dimensions. Quantitative imaging in medicine and surgery 2014; 4: $300-$ 306

27 Russo V, Renzulli M, La Palombara C et al. Congenital diseases of the thoracic aorta. Role of MRI and MRA. Eur Radiol 2006; 16: 676-684

28 Potthast S, Mitsumori L, Stanescu LA et al. Measuring aortic diameter with different MR techniques: comparison of three-dimensional (3D) navigated steady-state free-precession (SSFP), 3D contrast-enhanced magnetic resonance angiography (CE-MRA), 2D T2 black blood, and 2D cine SSFP. J Magn Reson Imaging 2010; 31: 177-184

29 Koos R, Altiok E, Mahnken AH et al. Evaluation of aortic root for definition of prosthesis size by magnetic resonance imaging and cardiac computed tomography: Implications for transcatheter aortic valve implantation. Int J Cardiol 2012; 158: $353-358$ 